:1. Theocaris, P. S. and Papadopoulos, G. A., "The Minimum Elastic Energy Density Criterion Dynamic Problems of Propagating Cracks," J. Engng. Materials and Technology, 104 p. 207 (1982)

2. Papadopoulos, G. A. and Theocaris, P. S., "The Influence of the Dynamic Modulus on Crack Propagation (1985).

13. Theocaris, P. S. and Andrianopoulos, N., "Propagation Predictions for Branched Cracks by the Strain Energy Density Criterion, J. Mech. Phys. Solids, 30, No. 1/2, p. 23 (1982).

4. Ramulu, M. and Kobayashi, A. S., "Strain Energy Density Fracture Criterion in Elastodynamic Mixed Mode Crack Propagation," Engng. Fract. Mech., 18, No. 6, p. 1087 (1983).

\section{Diffusion Studies on Advanced Fibre Hybrid Composites}

\author{
R. Gopalan, R. M. V. G. K. RaO And M. V. V. Murthy \\ National Aeronautical Laboratory \\ Bangalore 560 01 7 INDIA \\ B. DATTAGURU \\ Indian Institute of Science \\ Bangalore 560 O12 INDIA \\ (Received January 29, 1985)
}

\section{ABSTRACT}

The moisture diffusion characteristics of simple (E-glass, Graphite and Kevlar) and hybrid (E-Glass-Graphite, Graphite-Kevlar and Kevlar-E-Glass) unidirectional composites have been studied at $296 \mathrm{~K}$ and $343 \mathrm{~K}$ under water immersion conditions. The equilibrium moisture content $(\boldsymbol{M}$,$) and diffusion coefficient (\boldsymbol{D}$,$) of Kevlar fibre com-$ posites are respectively as high as $\mathbf{5}$ and $\mathbf{1 0}$ times those of E-glass/Graphite fibre composites. The hybridization of impermeable fibres (E-Glass and Graphite) in a composite does not cause significant changes in the $M_{m}$ and $D_{x}$ values of their simple composites. Hybridization of impermeable fibres with permeable fibres (Kevlar), however, has a significant effect on the diffusion characteristics of their simple composites. The experimental data for simple and hybrid composites comprising both impermeable and/or permeable fibre composites show good correlations with the analytical Fickian Diffusion plot. The effect of edge coating on the moisture absorption is quite significant in the impermeable fibre composites.

\section{INTRODUCTION}

TIGH PERFORMANCE COMPOSITES ARE BEING INCREASINGLY USED IN Iaerospace and marine structural applications. Unlike metallic materials, composites are susceptible to moisture and temperature when exposed to working environments. These environmental effects are known to cause degradation of the composite and consequent loss of mechanical properties. Considerable efforts have been made bv researchers to studv the effects of moisture and temperature, and to develop analytical models for the diffusion process in various composites. Shen and Springer $\{1,2,3]$ have presented extensive work on the moisture absorption behaviour of neat epoxy resin, glass and graphite fibre composites, based on a Fickian diffusion model. Similar Work has been reported by many authors [4] for these composites. The type inal of REINFORCED Plastics AND COMPOSITES, Vol. 5-January 1986 
of fibres studied by these investigators could be classified as impermeable fibres. On the other hand, studies on permeable types of fibre composites are rather scant. A composite with Kevlar fibres is a specific example. Despite the growing significance of Kevlar composites as advanced aerospace materials, relatively little has been reported on hygrothermal effects on these composites 44]. Augul and Allred [5] studied the moisture absorption and diffusion behaviour of Kevlar 49 aramid fibres and reported a moisture increase of more than $5 \%$ when they are exposed to water immersion. S. Y. Lo [6] studied the swelling of Kevlar $\mathbf{4 9}$ composites and reported a moisture increase of $5.5 \%$ under similar conditions. However no attempts have been made so far to verify the adequacy of a Fickian model for describing the moisture diffusion process in Kevlar composites in particular and hybrid fibre composites in general.

An attempt to check the Fickian model for permeable fibre polymer cornposites was made by Rao et al $[7,8,9]$. They carried out comprehensive investigations on the diffusion phenomenon in these composites, considering the natural fibres (jute). The jute fibre was considered to be permeable both to moisture and to matrix resin.

The diffusion studies are generally carried out on specimens with a permeable edge coating. However, this may not be adequate to predict the moisture content in a realistic aircraft or marine composite structure with a microcrack on the surface, or a typical mechanical joint with a bolt hole often exposed to the atmosphere. To understand the effect of edge coating on moisture absorption behaviour, specimens without a permeable edge coating, and coating on two edges (along and across the fibre direction) were fabricated and studied.

In this paper, experimental results are presented on moisture diffusion in E-glass, Graphite and Kevlar composites and hybrid composites comprised of E-glass-Graphite, Graphite-Kevlar and Kevlar-E-glass, all in an epoxy matrix. The investigations are carried out on the following aspects:

- The effect of hybridization of impermeable and/or permeable fibres on the $M_{\mathrm{m}}$ and $D_{\mathrm{x}}$ values.

- Verification of the adequacy of Fick's law to characterise the hybrid composites comprised of permeable and impermeable fibres.

- Study of the effect of edge coating on the $M_{m}$ and $D_{x}$ values of permeable and impermeable fibre composites.

\section{ANALYTICAL MODEL}

The one-dimensional moisture diffusion process taking place through two large opposite faces of an infinite plate is shown in Figure 1 and can be described by Fick's second law of diffusion,

$$
\frac{\partial c}{a t}=D_{x} \frac{a^{2} c}{\partial x^{2}}
$$

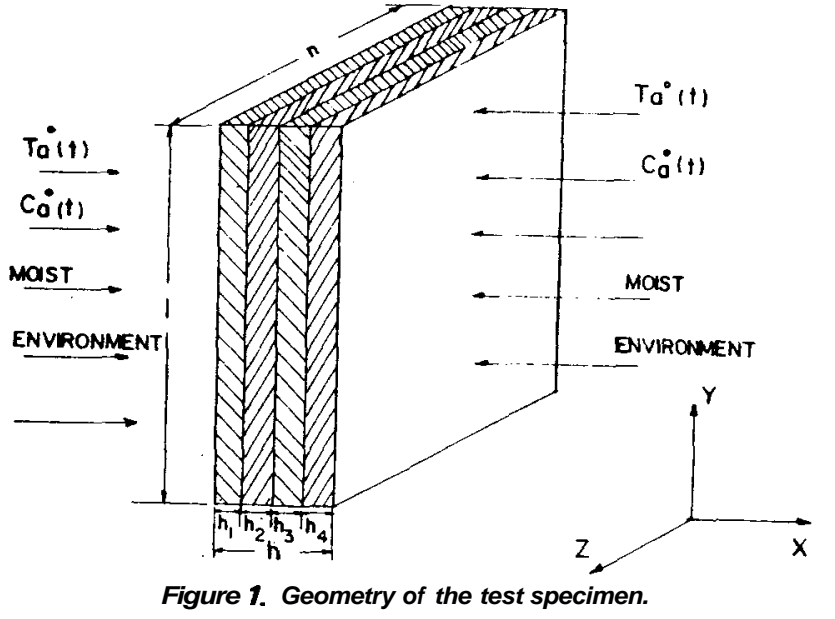

where

$t=$ time

$x=$ space coordinate in the direction of , sheet thickness

$\mathrm{c}=$ concentration of diffusant

$D_{x}=$ diffusion coefficient for the material

The boundary conditions are

$$
\begin{array}{lll}
c=c_{i} & 0<x<h & \\
c=c_{a} & x=0 ; x=h & t>0
\end{array}
$$

The solution for Equation (1) with the above boundary conditions as given by Crank is

$$
\frac{C_{a}-C_{i}}{C_{m}-C_{i}}=1-\frac{4}{\pi} \sum_{j=o}^{\infty} \frac{1}{(2 j+1)} \frac{(2 j+1) \pi X}{h} \exp \left[-(2 j+1)^{2} \pi^{2} \frac{D_{x} t}{h^{2}}\right]
$$

The total weight of moisture absorbed is obtained by integrating Equation (3) over the Plate thickness $h$.

$$
M=A \int_{0}^{h} c d x
$$

Where $A$ is the exposed surface area.

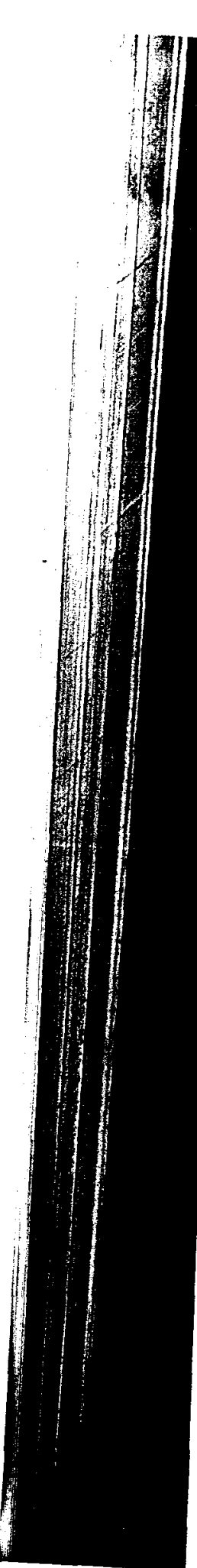


The result of the integration is

$$
G=\frac{M_{i}-M_{i}}{M_{m}-M_{i}}=1-\frac{8}{\pi^{2}} \sum_{j=o}^{\infty}\left[-\frac{\left.(2 j+1)^{2}\left(\frac{D_{x} t}{h^{2}}\right)^{2}\right]}{(2 \mathrm{j}+}\right.
$$

where $M_{i}$ is the initial weight of the moisture in the material and $M_{m}$ is the weight of the moisture in the material when fully saturated.

The diffusion coefficient $D_{x}$ can be deduced from the initial slope of the $M_{m}$ versus $\sqrt{l}$ curve, since

$$
D_{x}=\pi\left(\frac{h}{4 M_{m}}\right)^{2}\left[\left(\frac{M_{2}-M_{1}}{\sqrt{t_{2}-t_{1}}}\right)^{2}\right]
$$

A plot of the dimensionless absorption parameter $(\mathrm{Mt} / \mathrm{Mm})$ vs the dimensionless diffusion parameter $\left(D_{x} t / h^{2}\right)$ represents the Fickian diffusion curve for the composite. A good fit of the experimental data with this curve, therefore, confirms the applicability of a Fickian diffusion model for the material under consideration.

\section{EXPERIMENTAL DETAILS}

\section{Materials}

The materials used in the present investigation are as follows:

1. Epoxy Resin LY 556 with Hardener HT 972 supplied by CIBA-GEIGY (INDIA) Ltd.

2. E-glass rovings supplied by Fibre Glass Pilkington, Bombay, India.

3. Graphite Fibres (HMS) supplied by Graphil and Company, U.K.

1. Kevlar-49 Fibres - Supplied by Du Pont Company, U.S.A.

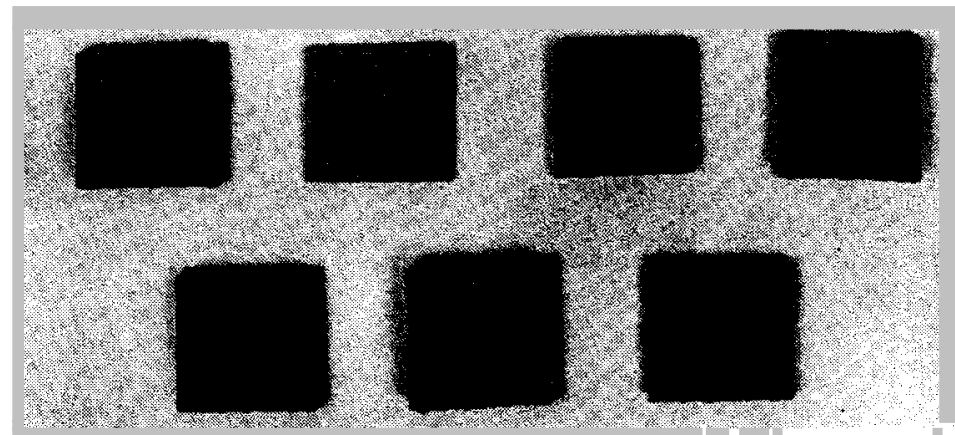

igure 2. Moisture absorption specimen: top: L-R: neat epoxy resin, E-G/ass-Epoxy, Graphite poxy and Kevlar-Epoxy, bottom: E-Glass-Graphite-Epoxy, Kevlar-E-Glass-Epoxy and GraphiteGlass-Epoxy composites.

\section{Specimen Preparation and Exposure}

Unidirectional laminates with E-glass, Graphite, Kevlar and E-GlassGraphite, Graphite-Kevlar and Kevlar-Glass in the epoxy resin were fabricated by filament winding technique. They were cured at $393 \mathbf{K}$ and 100 Psi pressure for 3 hours. A fibre volume ratio of around $70 \%$ by weight was maintained in the above composites. Test specimens of $25 \mathrm{~mm} \times 25 \mathrm{~mm} \times 2$ $\mathrm{mm}$ were cut from the laminates by using a high speed diamond cutter. Kevlar and Kevlar-based composite laminates were cut by using a $0.2 \mathrm{~mm}$ slit ting saw by a milling technique. The specimens used for the present studies are shown in Figure 2.

All the test specimens were edge coated and post cured at $373 \mathrm{~K}$ for 1 hour. They were then dried to constant weight to obtain bone dry specimens. The weights of the specimens were obtained using a precision single pan electronic balance to an accuracy of $0.001 \mathrm{gms}$. The bone dry specimens were then immersed in water maintained at $296 \mathrm{~K}$ and $343 \mathrm{~K}$.

The weight gain of the specimens was carefully monitered by weighing them periodically. Precautions were taken to remove the surface moisture from all specimens by carefully wiping them off each time before weighing. The percentage weight gained in the specimen is calculated as follows;

$$
M(\%)=\frac{W_{2}-W_{1}}{W_{1}} \times 100
$$

where $W_{2}$ is the weight of the wet specimen $W_{1}$ is the weight of the dry specimen

The percentage weight gains were then plotted against $\sqrt{t}$ to generate the moisture absorption curves necessary to calculate the composite diffusion coefficients. Each point in the plots is the average of $\mathbf{6}$ data points.

\section{RESULTS AND DISCUSSION}

The results of the experimental investigations are shown in Tables 1 and 2 and Figures 3 thru 8 . Figure 3 shows the moisture absorption curves at $296 \mathbf{K}$ and $343 \mathrm{~K}$ for neat epoxy resin as well as E-glass, Graphite, and Kevlar fibre composite specimens. Figure 4 shows the moisture absorption curves for hybrid composites, viz. E-glass, Graphite, Graphite-Kevlar and Kevlar-EGlass composites. The diffusion coefficients $\left(D_{x}\right)$ for these composites are calculated using Equation (6) and are shown in Table 1.

From Table 1 it is clearly seen that the Kevlar fibre composites absorb moisture as high as 4-5 times that of E-Glass and Graphite fibre composites. Also, the diffusion co-efficient of Kevlar fibre composites is as high as 10 times that of E-Glass and Graphite fibre composites. This confirms the high Permeability of Kevlar fibre composites to moisture.

Plots between the dimensionless absorption $\left(M, M_{m}\right)$ and diffusion coeffici $_{\text {ent }}\left(D_{x} t / h^{2}\right)$ parameters for simple and hybrid composites at $296 \mathrm{~K}$ and 


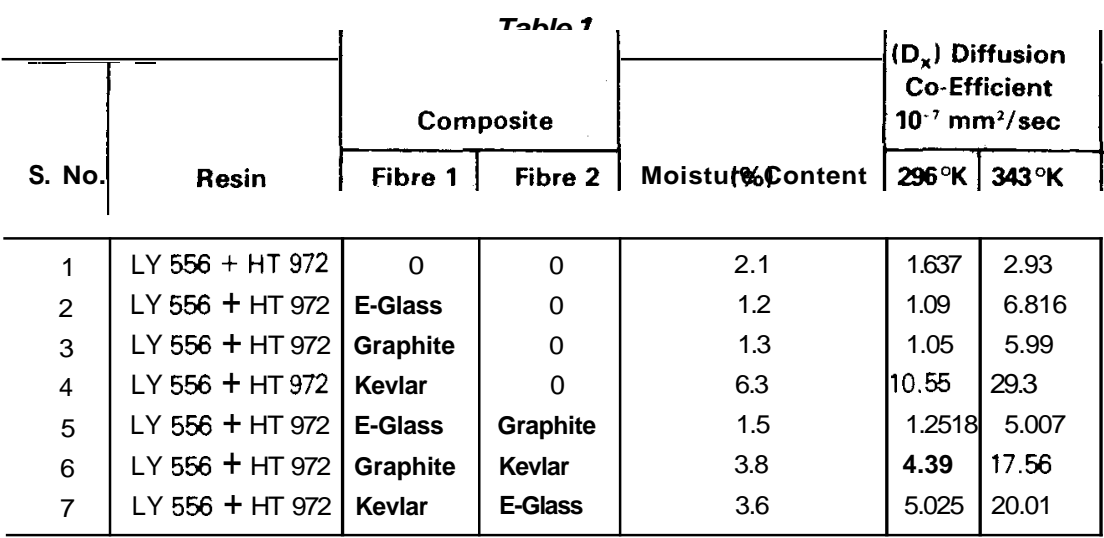

\begin{tabular}{|c|c|c|c|c|c|c|}
\hline \multirow[b]{2}{*}{ SI. No } & \multicolumn{2}{|c|}{ Composite } & \multicolumn{4}{|c|}{ Maximum Moisture Content } \\
\hline & Fibre 1 & Fibre 2 & $\begin{array}{l}\text { III Sides } \\
\text { Coated }\end{array}$ & $\begin{array}{l}\text { All Sides } \\
\text { Jot Coater }\end{array}$ & $\begin{array}{l}\text { 'wo Sides' } \\
\text { Coated }\end{array}$ & $\begin{array}{l}\text { Two Sides"- } \\
\text { Coated }\end{array}$ \\
\hline 1 & $\begin{array}{l}\text { E-Glass } \\
\text { (unidirectional) }\end{array}$ & 0 & 1.2 & 1.4 & 1.26 & 2.17 \\
\hline 2 & $\begin{array}{l}\text { Graphite } \\
\text { (unidirectional) }\end{array}$ & 0 & 1.3 & 2.64 & 1.43 & 2.55 \\
\hline 3 & Kevlar & 0 & 6.3 & 6.8 & 6.32 & 6.7 \\
\hline 4 & $\begin{array}{l}\text { E-Glass } \\
\text { (bi-directional) }\end{array}$ & 0 & 2.1 & 2.6 & - & - \\
\hline 5 & $\begin{array}{l}\text { Graphite } \\
\text { (bi-directional) }\end{array}$ & 0 & 2.3 & 2.8 & - & - \\
\hline 6 & E-Glass & jraphite & 1.12 & 2.78 & 1.6 & 2.6 \\
\hline 7 & Graphite & éevlar & 3.56 & 3.62 & - & - \\
\hline 8 & Kevlar & -Glass & 3.39 & 3.49 & - & - \\
\hline
\end{tabular}

'Along the fibre direction.

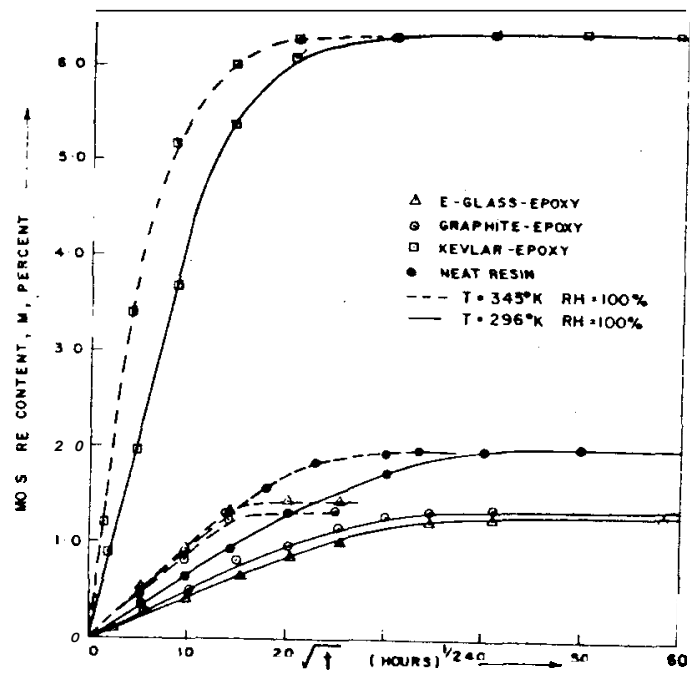

figure 3. Moisture absorption (\%) vs time for permeable and impermeable fibre simple com posites.

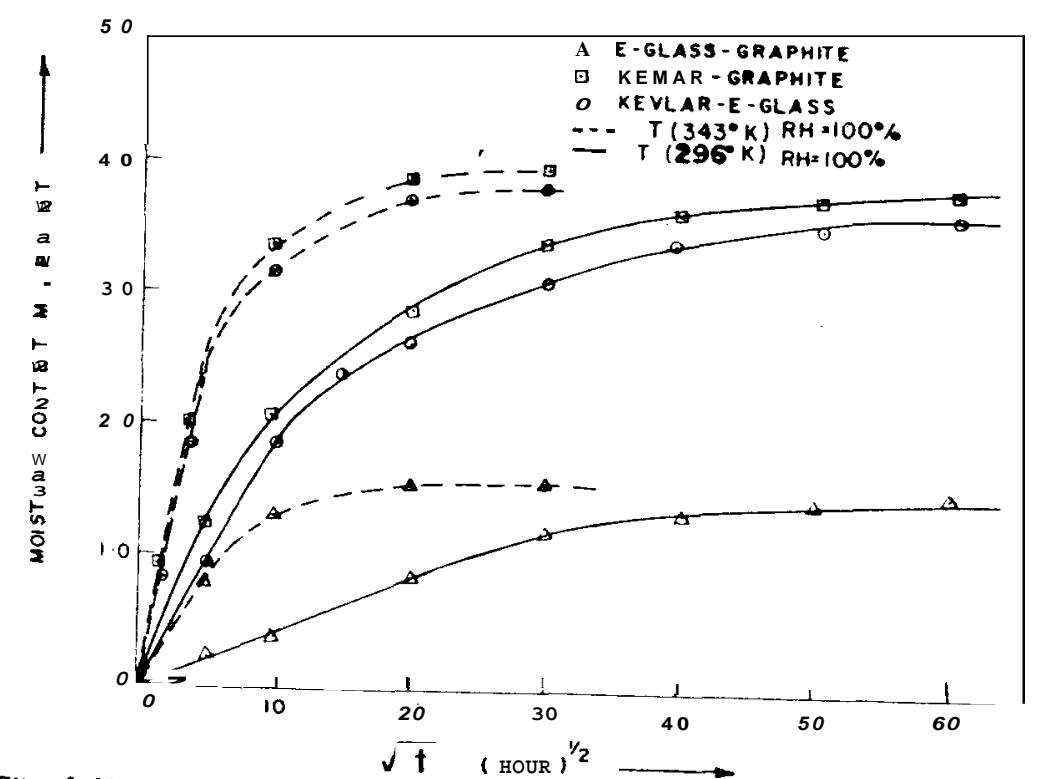

Figure 4. Moisture absorptton 1\%) vs time for permeable and impermeable fibre hybrtd com posites. 


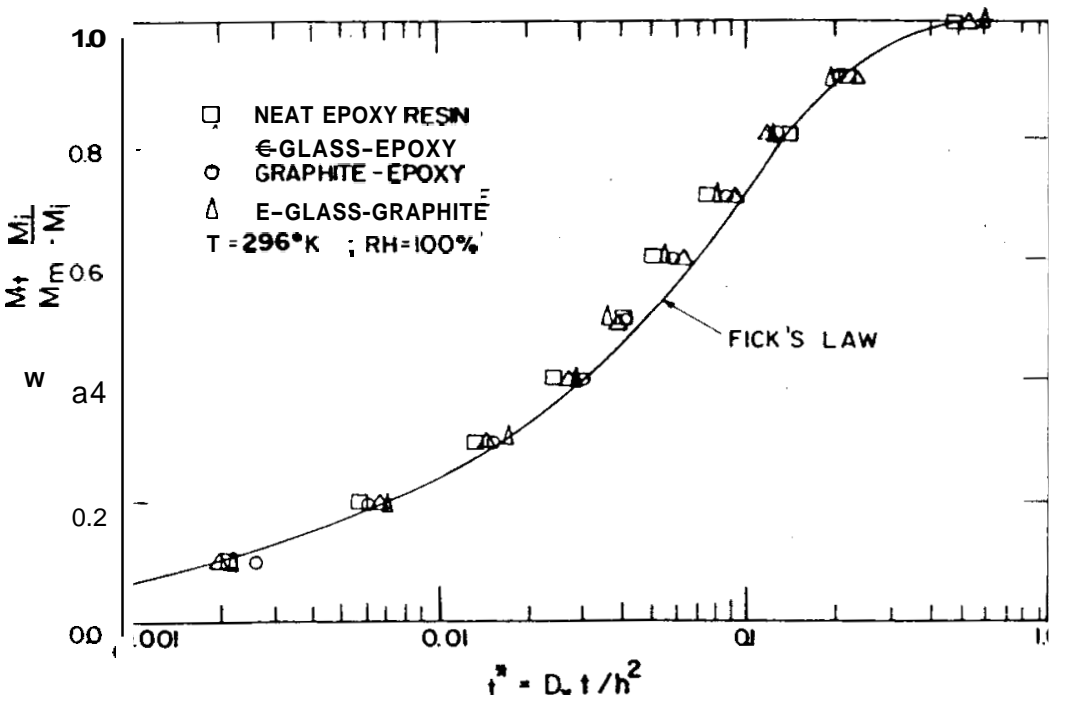

zure 5. Fickian distribution for simple and hybrid impermeable fibre Composites at room nperature $\left(T=296^{\circ} \mathrm{K}\right)$
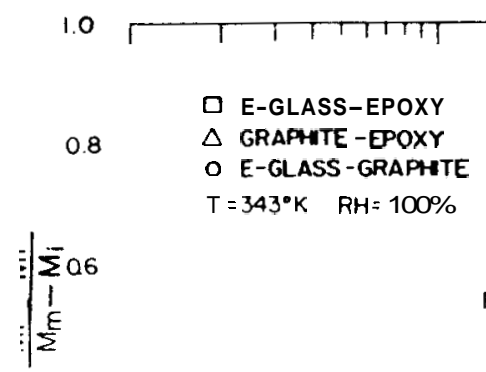

0.4

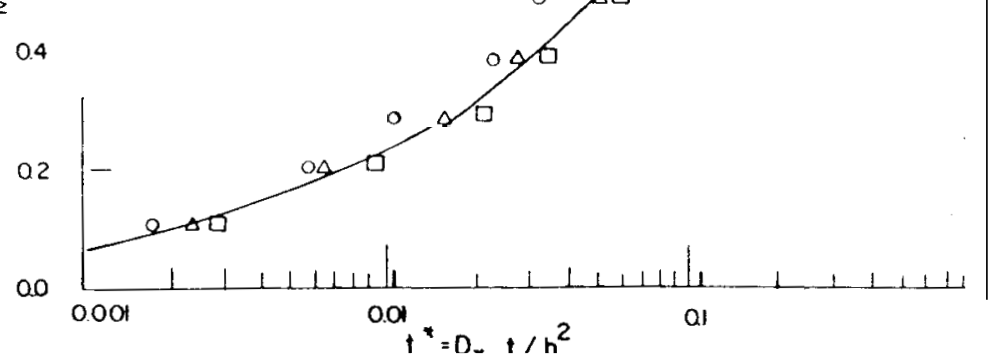

ure 6. Fickian distribution for simple and hybrid impermeable fibre composites at high iperature $\left(T=343^{\circ} \mathrm{K}\right)$

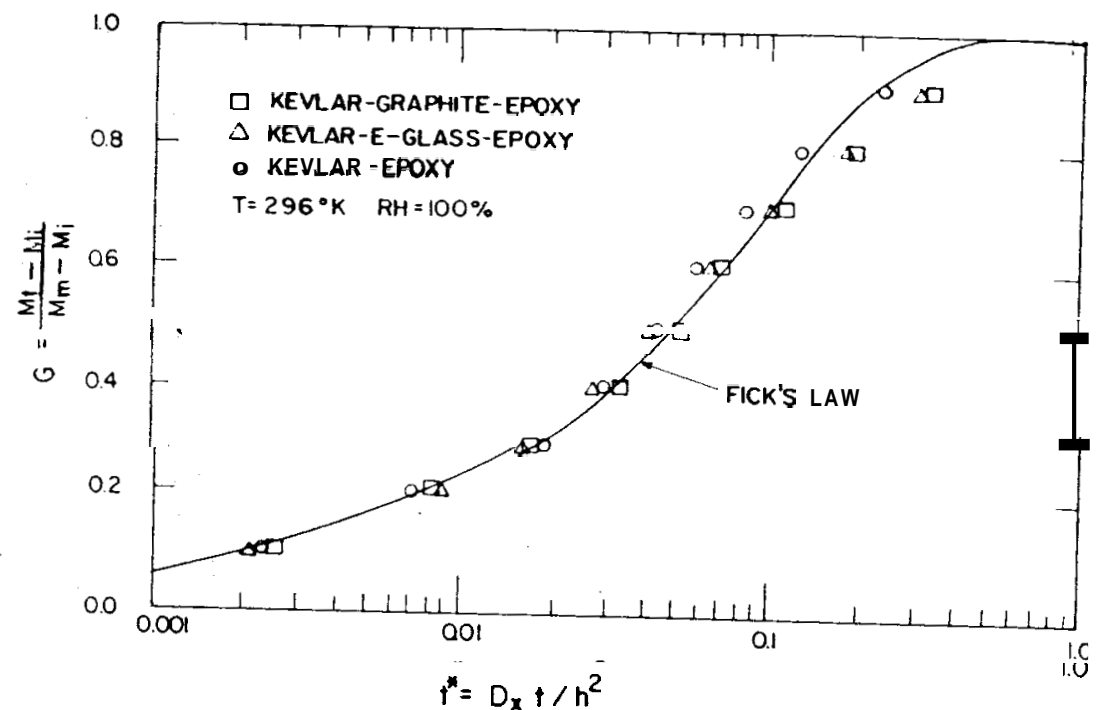

figure 7. Fickian distribution for simple and hybrid, permeable fibre composites at room temperature $\left(T=296^{\circ} \mathrm{K}\right)$.

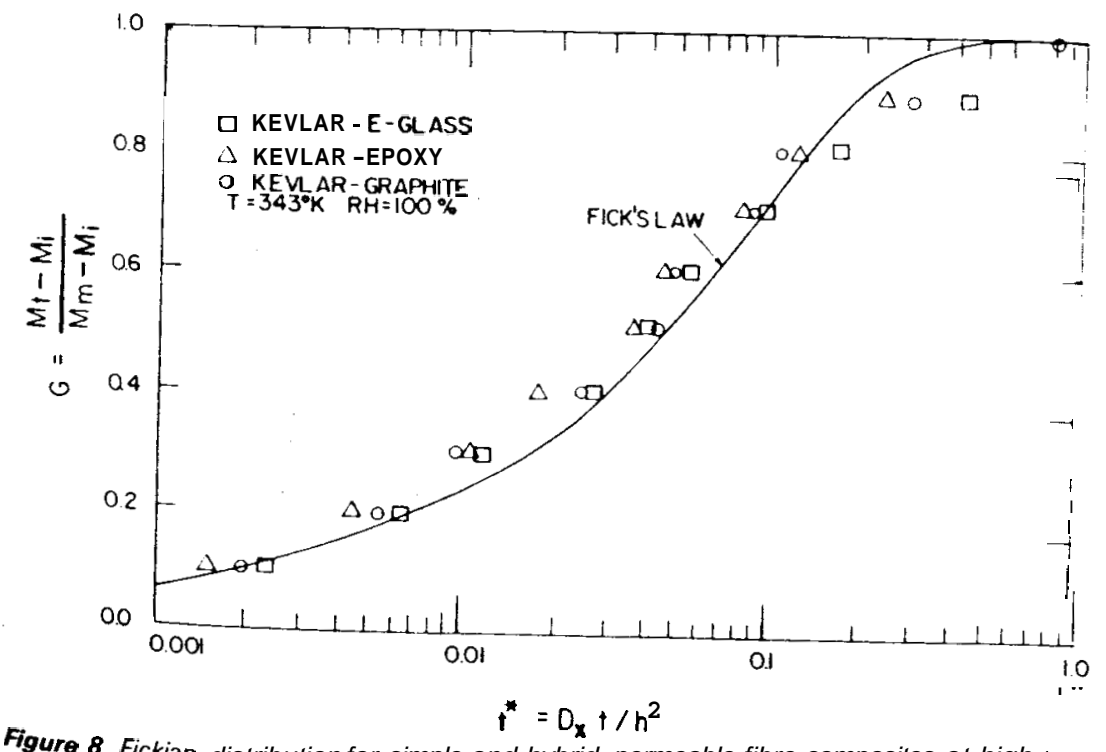

Figure 8. Fickian distribution for simple and hybrid, permeable fibre composites at high tem. perature $\left(T=343^{\circ} \mathrm{K}\right)$. 
also can be adequately represented by a Fickian diffusion model, even though they are highly permeable to moisture.

Table 2 shows the effect of edge coating on the equilibrium moisture content in permeable and impermeable fibre composites. In the case of impermeable fibre composites the effect of edge coating is significant, whereas in the permeable fibre composites this effect is relatively insignificant. The difference is apparently due to the high permeability of the Kevlar fibers. The insignificant effect of edge coating in this permeable fibre composite shows that its diffusion coefficient is not as direction sensitive as that of the Dermeable fibre composites. Similar observations were made by Rao et al, while reporting on the natural fibre composites.

\section{CONCLUSIONS}

The equilibrium moisture content and diffusion coefficient of Kevlar fibre composites are as high as 5 and 10 times that of the E-glass/Graphite fibre composites, respectively. Based on the moisture absorption levels, it is appropriate to consider Kevlar fibres as permeable and E-glass/Graphite fibres as impermeable to moisture.

Hybridization of impermeable fibres in a composite does not cause a significant change in the saturated moisture content and diffusion coefficient values of their simple Composites. These composites show lower saturated moisture contents and diffusion coefficients as compared to Kevlar fibre composites.

The moisture content and diffusion coefficient of Kevlar composites increase with the increase in fibre volume ratio, confirming the permeable nature of these fibres. Hybridization of impermeable and permeable fibres in a composite has a significant influence on the diffusion characteristics of composites based on either class of fibres.

Experimental data for simple and hybrid composites comprised of both permeable and impermeable fibres have good correlation with the analytical Fickian diffusion model and hence the Fickian model is adequate to characterise these composites for the through-thickness moisture diffusion.

Edge coating has a significant effect on the saturated moisture content in impermeable fibre composites. The saturated moisture content in the uncoated specimens is nearly twice that of the coated specimens. Edge coating does not have a significant effect on the saturated moisture content in permeable fibre composites and hence the diffusion coefficient is not greatly affected by the direction of moisture diffusion.

Kevlar fibre composites exhibit a colour change after saturation, from yellow to dark brown.

\section{ACKNOWLEDGEMENTS}

The authors are very thankful to the Director, National Aeronautical Laboratory, and B. R. Somashekar, Head, Structures Division, for their sup- port in these investigations. The assistance provided by B. Ramanaiah at various stages of this investigation is highly appreciated.

\section{REFERENCES}

1. Shen, Chi-Hung and Springer, George S., "Moisture Absorption of Composite Materials," Composite Materials, Vol. 10 (1979).

2. Loos, Alfred C. and Springer, George S., "Moisture Absorption of Graphite-Epoxy Composites Immersed in Liquids and in Humid Air," J. Comp. Materials, Vol. 13 (April 1979).

3. Loos, Alfred C. and Springer, George S., "Moisture Absorption of Polyester-E-Glass Composites,” J. Comp. Materials, Vol. 14 (April 1979).

4. Komorowshi, J. P., "Hygrothermal Effects in Continuous Fibre Reinforced Composites Part I : Thermal and Moisture Diffusion in Composite hlaterials," NAG-AN-4, 20974 (January I: The.

5. Augul and Allred, "Moisture Absorption and Diffusion in Kevlar 49 Aramid Fiber," NSWC/TR-79-51 (March 1979).

6. Lo, S. Y. and Hahn, H. T., "Swelling of Kevlar 49/Epoxy and S2-Glass/Epoxy Composites," Progress in Science and Engineering of Composites (1982).

7. Rao, R. M. V. G. K., Balasubramanian, N. and Chanda, Manas "Moisture Absorption Phenomenon in Permeable Fiber Polymer 'Composites," J. Applied Polymer Science, Vol. (1981).

8. Rao, R. M. V. G. K., Chanda, Manas and Balasubramanian, N., “A Fickian Diffusion Model for Permeable Fibre Polymer Composites," $J$. Reinforced Pla "A Fickian Diffusion 9. Rao, R. M. V. G. K., et al.. "Factors Affecting Moisture Absorption in Polymer Composites-Part I and II," J. Reinforced Plastics and Composites (July 1984). 